\title{
Ixodid Ticks on Oertzen's Rock Lizard (Anatololacerta oertzeni) on Ilkaria, Greece, with Notes on the Island's Reptiles
}

\author{
Steven J.R. Allain ${ }^{1}$ and Talita C.B. Bateman ${ }^{2}$ \\ ${ }^{1} 11$ Trafalgar Way, Braintree, Essex, UK (steveallain@live.co.uk) \\ 211b Hamilton Park, London, UK (hello@talitabateman.com)
}

$\mathrm{I}$ karia is a small $\left(-255 \mathrm{~km}^{2}\right)$ Greek island in the Aegean Sea. The island has montane areas with elevations in excess of $1,000 \mathrm{~m}$ and many small mountain streams and rivers (Clark 1996). Ikaria is covered with thick vegetation, especially along the banks of streams and rivers. Ikaria is home to 11 reptilian species (Table 1). Clark (1996) recorded six of these species while visiting the island three times between 1966 and 1995 , and speculated that additional species might be found in the island's interior wilderness. Interestingly, Speybroeck et al. (2016) listed ten species but failed to include Oertzen's Rock Lizard (Anatololacerta oertzeni), although the authors did list $A$. anatolica as occurring on Ikaria. These species are very similar, and $A$. anatolica does occur on the neighboring island of Samos (Bellati et al. 2015). The taxonomy of this group of lizards has long been disputed (e.g., Candan et al. 2016) and confusion persists due to the various taxonomies used by different authors and authorities (e.g., Arnold et al. 2007).

On 19 and 21 July 2017, we conducted counts of local lizard species at a small $\left(\neg 7 \mathrm{~m}^{2}\right)$ site roughly $1.2 \mathrm{~km}$ from the village of Vrakades along a footpath leading to the village of Lahkada (Fig. 1). The study site is situated between a large set of boulders and a small flooded "reservoir" and is characterized by low vegetation. The lack of roads and multiple dirt tracks make for good walking and provide an ideal opportunity to observe reptiles in their natural habitat.

Ikaria is also home to two "Natura 2000" sites (Hadjigeorgiou and Zervas 2009), one addressing the Birds Directive (GR4120005) and another addressing the Habitats Directive (GR4120004). The survey site is found within the boundaries of the latter, where the Caspian Terrapin

Table 1. A comprehensive checklist of the reptiles that inhabit Ikaria.

Species

Reference(s)

Balkan Terrapin (Mauremys rivulata)

Clark (1996), Arnold and Ovenden (2002), Valakos et al. (2008), Speybroeck et al. (2016)

Caspian Whipsnake (Dolichophis caspius)

Clark (1996), Valakos et al. (2008), Speybroeck et al. (2016)

European Catsnake (Telescopus fallax)

Speybroeck et al. (2016)

Grass Snake (Natrix natrix)

Speybroeck et al. (2016)

Pallas's Glass Lizard (Pseudopus apodus)

Valakos et al. (2008), Speybroeck et al. (2016)

Starred Agama (Stellagama stellio)

Clark (1996), Arnold and Ovenden (2002), Valakos et al. (2008), Speybroeck et al. (2016)

\begin{tabular}{ll}
\hline Mediterranean House Gecko (Hemidactylus turcicus) & Valakos et al. (2008), Speybroeck et al. (2016) \\
\hline Kotschy's Gecko (Mediodactylus kotschyi) & Clark (1996), Valakos et al. (2008), Speybroeck et al. (2016) \\
\hline Snake-eyed Lizard (Ophisops elegans) & $\begin{array}{l}\text { Clark (1996), Arnold and Ovenden (2002), Valakos et al. (2008), } \\
\text { Speybroeck et al. (2016) }\end{array}$ \\
\hline Oertzen's Rock Lizard (Anatololacerta oertzeni) & Clark (1996), Valakos et al. (2008) \\
\hline European Snake-eyed Skink (Ablepharus kitaibelii) & Valakos et al. (2008), Speybroeck et al. (2016) \\
\hline
\end{tabular}




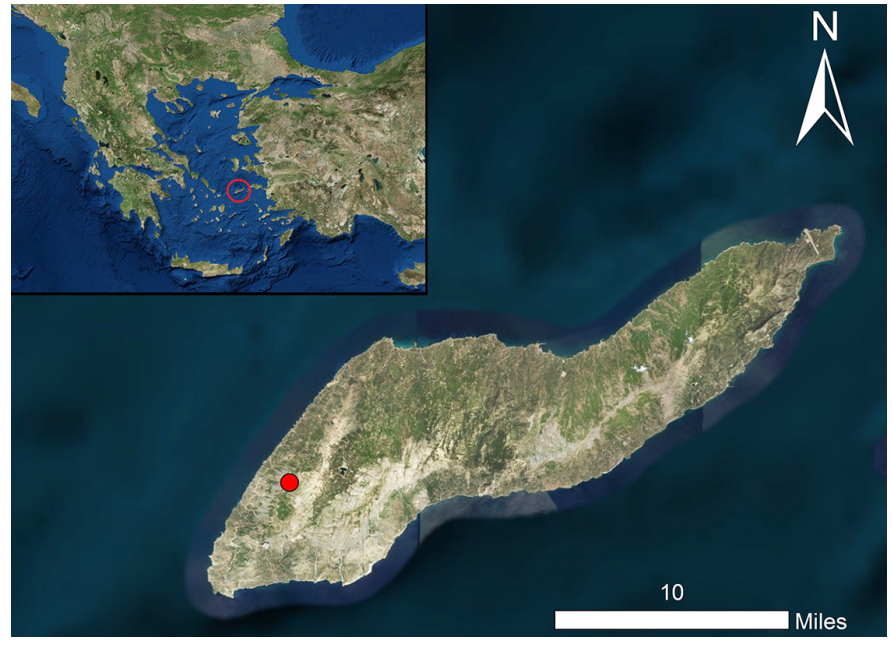

Fig. 1. Google Earth $^{\odot}$ map of Ikaria showing the location of the study site (red dot).

(Mauremys caspica) is listed as the only protected reptile species. This is particularly perplexing as $M$. rivulata is the only terrapin species found on the island and the two species are generally considered to be parapatric (Broggi 2012).

The focal species for our informal study was Oertzen's Rock Lizard (A. oertzeni), which is so abundant on the island that locals refer to it as the "Lizard of Ikaria." On both dates, we began our one-hour surveys at approximately $1100 \mathrm{~h}$. We observed lizards chasing competitors, hunting potential prey, and basking on rocky outcrops. We recorded a peak count of five adults, of which two were infected with hard ticks of the family Ixodidae (Fig. 3), and 15 juveniles, approximately $10-15 \mathrm{~cm}$ in length, which we easily identified by their bright blue/turquoise tails. We also encountered a number of Starred Agamas (Stellagama stellio) basking on and along the trail to the study site, but did not record numbers.

We noticed that the most heavily tick-infested individual (Fig. 2) was chased out of the most optimal basking sites by the other adults. Bauwens et al. (1983) suggested that infected lizards might have poorer body condition, reduced social status, and lower reproductive output compared with non-infected lizards. Although ticks usually attach to areas around the ears, limbs, and in folds of skin (Schneller and Pantchev 2008), the ticks on the infected rock lizards were on exposed areas. This could be because these ticks have evolved a special preference for the flanks of lizards, as in species such as Ixodes asanumai (Dudek et al. 2016). The ticks were not engorged and because ticks are not known to engage in phoresis (mechanical transport by a host; Beccaloni 2009), they likely had attached only recently to the lizards.

This is the first report of ticks infecting a reptile on the island of Ikaria, but ticks are known to infect reptiles elsewhere in Greece and nearby Turkey (Hoogstraal 1959; Široký et al. 2006). We did not see ticks on any Starred Agamas, but other reptilian species on Ikaria are likely to be infected.

We were unable to identify the species of ticks due to small size, lack of quality photographs, and the similar-

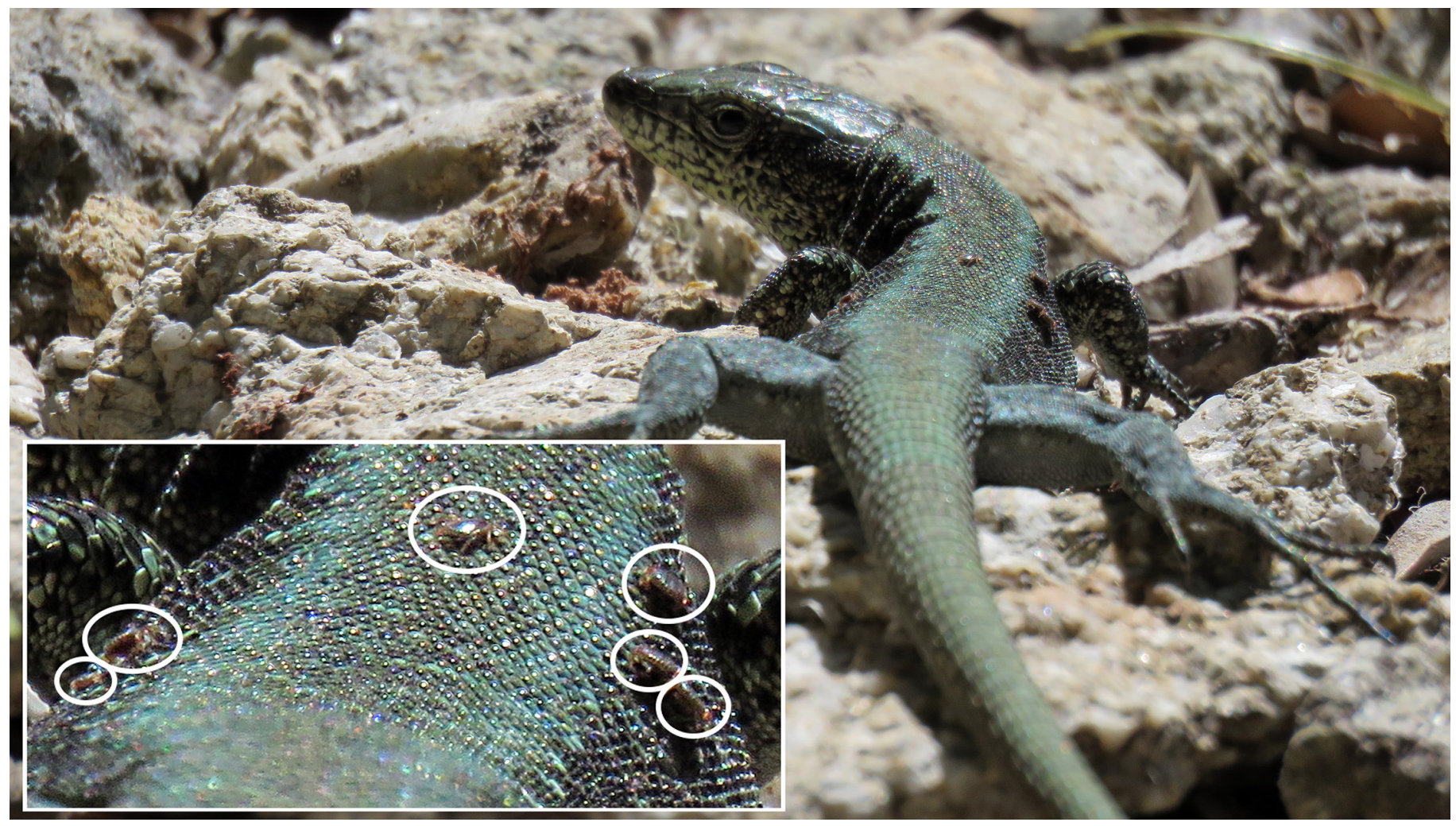

Fig. 2. At least six ticks can be seen on the flanks and back of the most heavily infected Oertzen's Rock Lizard (Anatololacerta oertzeni) from a study site on the Greek island of Ikaria. Photograph by Talita C.B. Bateman. 


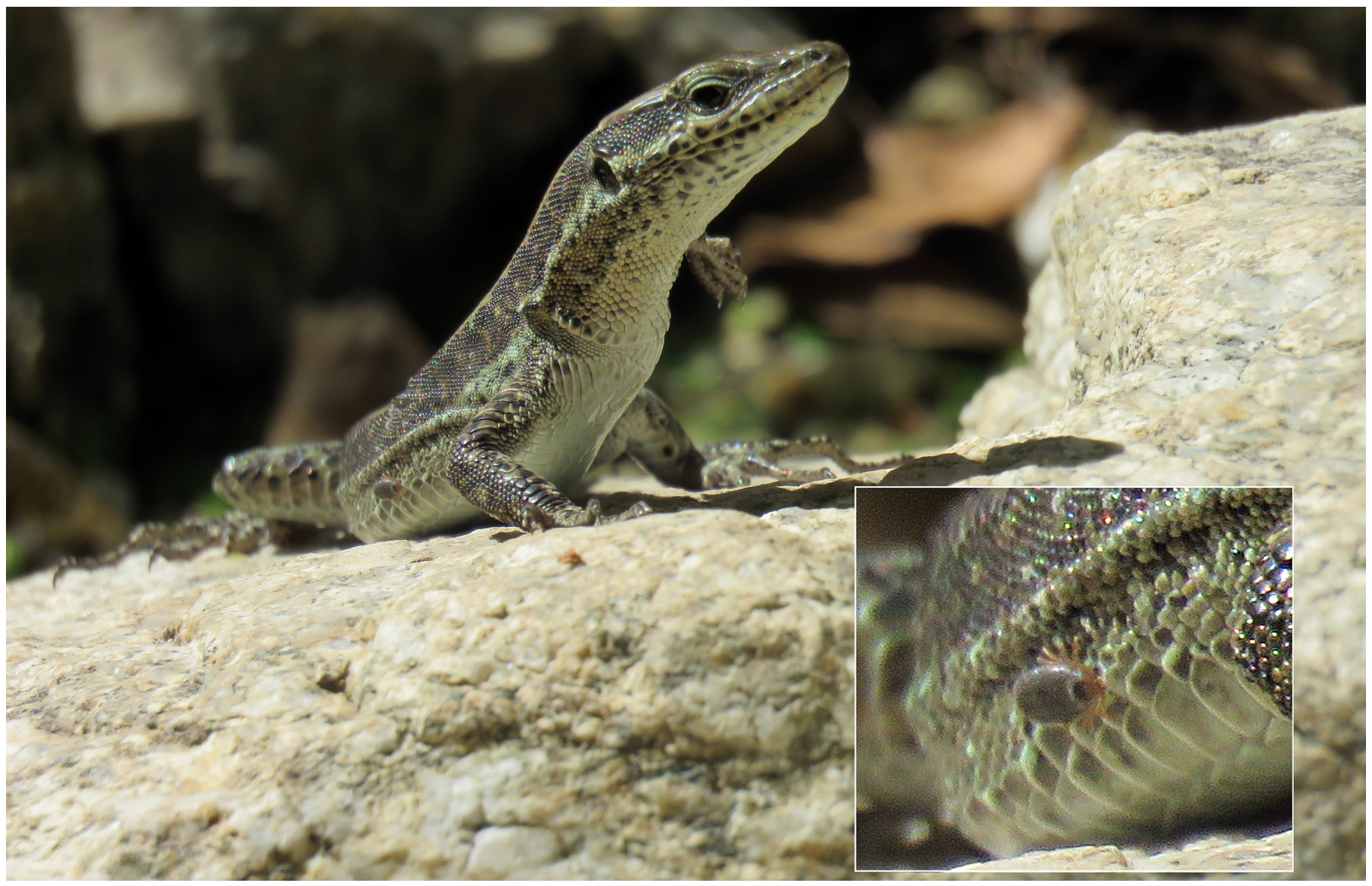

Fig. 3. A tick on an Oertzen's Rock Lizard's (Anatololacerta oertzeni) flank clearly shows four pairs of legs, indicating that the tick is either a nymph or an adult. Photograph by Talita C.B. Bateman.

ity of a number of species (Estrada-Peña et al. 2018). The ticks probably are in the genus Dermacentor, Hyalomma, or Ixodes and might represent more than one species or life stage. Ruminants (goats and sheep) are abundant in the area and might facilitate dispersal (e.g., Chaligiannis et al. 2016; Dimanopoulou et al. 2017).

\section{Literature Cited}

Arnold, N. and D. Ovenden. 2002. Reptiles and Amphibians of Britain and Europe. New edition. HarperCollins Publishers, London, UK.

Arnold, E.N., O. Arribas, and S. Carranza. 2007. Systematics of the Palaearctic and Oriental lizard tribe Lacertini (Squamata: Lacertidae: Lacertinae), with descriptions of eight new genera. Zootaxa 1430: 1-86.

Bauwens, D., H. Strijbosch, and A.H. Stumpel. 1983. The lizards Lacerta agilis and L. vivipara as hosts to larvae and nymphs of the tick Ixodes ricinus. Ecography 6: $32-40$.

Beccaloni, J. 2009. Arachnids. University of California Press, Oakland, California.

Bellati, A., S. Carranza, J. Garcia-Porta, M. Fasola, and R. Sindaco. 2015. Cryptic diversity within the Anatololacerta species complex (Squamata: Lacertidae) in the Anatolian Peninsula: Evidence from a multi-locus approach. Molecular Phylogenetics and Evolution 82: 219-233.

Broggi, M.F. 2012. The Balkan Terrapin Mauremys rivulata (Valenciennes, 1833), in the Aegean islands. Threats, conservation aspects and the situation on the island of Kea (Cyclades) as a case study (Testudines: Geoemydidae). Die Ostmediterrane Bachschildkröte, Mauremys rivulata (Valenciennes, 1833), auf den Inseln der Ägäis. Naturschutzaspekte und die Situation auf der Insel Kea (Kykladen) als Fallbeispiel (Testudines: Geoemydidae). Herpetozoa 24: 149-163.
Candan, K., T. Kankılıç, Ö. Güçlü, Y. Kumlutaş, S.H. Durmuş, P. Lymberakis, N. Poulakakis, and C. Ilgaz. 2016. First assessment on the molecular phylogeny of Anatololacerta (Squamata, Lacertidae) distributed in Southern Anatolia: Insights from mtDNA and nDNA markers. Mitochondrial DNA 27: 2285-2292.

Chaligiannis, I., V. Musella, L. Rinaldi, G. Cringoli, J. de la Fuente, A. Papa, and S. Sotiraki. 2016. Species diversity and spatial distribution of ixodid ticks on small ruminants in Greece. Parasitology Research 115: 4673-4680.

Clark, R. 1996. Some notes on the reptile fauna of Foumoi, Ikaria, and Schinoussa, Aegean Sea, Greece. The Herpetological Bulletin 56: 35-39.

Dimanopoulou, A.P., A.G. Starras, A. Diakou, M. Lefkaditis, and N.D. Giadinis. 2017. Prevalence of tick species in sheep and goat flocks in areas of southern Greece. Journal of the Hellenic Veterinary Medical Society 68: 205-210.

Dudek, K., P. Skórka, Z.A. Sajkowska, A. Ekner-Grzyb, M. Dudek, and P. Tryjanowski. 2016. Distribution pattern and number of ticks on lizards. Ticks and Tick-borne Diseases 7: 172-179.

Estrada-Peña, A., A.D. Mihalca, and T.N. Petney (eds.). 2018. Ticks of Europe and North Africa. A Guide to Species Identification. Springer International Publishing AG, Cham, Switzerland.

Hadjigeorgiou, I. and G. Zervas. 2009. Evaluation of production systems in protected areas: Case studies on the Greek "Natura 2000" network, pp. 101-111. In: F. Pacheco and F. Morand-Fehr (eds.), Changes in Sheep and Goat Farming Systems at the Beginning of the 21st Century. Research, Tools, Methods and Initiatives in Favour of a Sustainable Development. Changement des modes de production et evolution de systems d'élevage ovin et caprin au début du XXIème siècle. Recherches, outils, méthodes et initiatives en faveur d'un développement durable. Options Méditerranéennes Series A: Mediterranean Seminars, No. 91. Centre International de Hautes Etudes Agronomiques Méditerranéennes/International Centre for Advanced Mediterranean Agronomic Studies, Bari, Italy.

Hoogstraal, H. 1959. Biological observations on certain Turkish Haemaphysalis ticks (Ixodoidea, Ixodidae). Journal of Parasitology 45: 227-232. 
Schneller, P. and N. Pantchev. 2008. Parasitology in Snakes, Lizards and Chelonians: A Husbandry Guide. Edition Chimaira, Franfurt am Main, Germany.

Široký, P., K.J. Petrželková, M. Kamler, A.D. Mihalca, and D. Modrý. 2006. Hyalomma aegyptium as dominant tick in tortoises of the genus Testudo in Balkan countries, with notes on its host preferences. Experimental and Applied Acarology 40: 279-290.
Speybroeck, J., W. Beukema, B. Bok, and J. van der Voort. 2016. Field Guide to the Reptiles and Amphibians of Britain and Europe. Bloomsbury Publishing, London, UK.

Valakos, E.D., P. Pafilis, K. Sotiropoulos, P. Lymberakis, P. Maragou, and J. Foufopoulos. 2008. The Amphibians and Reptiles of Greece. Edition Chimaira, Franfurt am Main, Germany. 